\title{
Similarities between trunk and spätzle, putative extracellular ligands specifying body pattern in Drosophila
}

\author{
Jordi Casanova, ${ }^{1}$ Marc Furriols, ${ }^{1}$ Carol Ann McCormick, ${ }^{2}$ and Gary Struhl ${ }^{2}$ \\ ${ }^{1}$ Centre d'Investigaciö i Desenvolupament (CSIC), Barcelona, Spain; ${ }^{2}$ Howard Hughes Medical Institute, Columbia \\ University College of Physicians and Surgeons, New York, New York 10032 USA
}

\begin{abstract}
The basic body plan of Drosophila is specified by four determinant systems that organize pattern along the anteroposterior and dorsoventral axes. Two of these systems (anterior and posterior) depend on localized mRNAs. In contrast, the other two (ventral and terminal) require locally generated extracellular ligands that are transduced, respectively, by the transmembrane receptors Toll and torso (tor). The ligand for the Toll receptor is thought to be spätzle (spz), a secreted protein that is activated by proteolytic cleavage. Here we report that trunk (trk), a gene required for activity of the tor receptor, encodes a protein that resembles spz in several respects. In particular, the sequence suggests that trk is a secreted protein and that it contains an internal site for proteolytic cleavage. Furthermore, the carboxy-terminal domain of trk has a similar arrangement of cysteines to that of spz. We propose that trk encodes an extracellular ligand involved in specifying terminal body pattern and suggest by analogy with spz that a cleaved form of trk constitutes the ligand for the tor receptor.
\end{abstract}

[Key Words: Drosophila; pattern formation; extracellular ligands; trunk; spätzle; signal transduction; torso]

Received August 10, 1995; revised version accepted September 5, 1995.

The early development of the Drosophila embryo is governed by localized determinants that are generated during oogenesis and then activated upon fertilization. These determinants fall into two classes: localized RNAs, such as bicoid (bcd) and nanos (nos), which are deposited at the anterior and posterior poles of the egg cell, and poorly understood extracellular components that appear to be associated with the vitelline membrane surrounding the egg cell, either at the poles or along the ventral surface. Following fertilization, $b c d$ and nos RNAs are translated and their protein products diffuse through the embryo, controlling most aspects of anteroposterior pattern by regulating the transcription of $z y-$ gotic gap genes such as giant, hunchback, Krüppel, and knirps. At the same time, the extracellular components along the ventral surface and at the poles appear to give rise to distinct ventral and terminal ligands that diffuse in the perivitelline fluid layer surrounding the embryo until they are bound and sequestered by the transmembrane receptors Toll and torso (tor). These receptors then transduce the ventral and terminal signals by regulating the transcription of dorsoventral genes (e.g., twist, snail, and zen) and additional gap genes (tailless and huckebein) (for review, see Nüsslein-Volhard et al. 1987; St. Johnston and Nüsslein-Volhard 1992).

The local generation of extracellular ligands in the perivitelline fluid layer is best understood for the dorsoventral system. In this case, a series of gene products have been identified that appear to constitute a processing system for generating the ligand. Some of these products [encoded by the nudel (ndl), windbeutel (wind), and pipe (pip) genes] appear to be made in the follicle cells that surround the egg cell and synthesize the vitelline membrane. Others are made by the oocyte or early embryo and appear to constitute both a putative ligand [encoded by the spätzle (spz) gene] and a protease cascade (encoded by the snake, easter, and gastrulation defective genes) that allows the processing and activation of the ligand in response to the local activities of ndl, wind, and pip gene products (for a review of the dorsoventral system, see Chasan and Anderson 1993).

The situation for generating the terminal signal is less well understood. Two genes, torso-like (tsI) and trunk (trk), have been identified that are essential for activity of the receptor, encoded by the tor gene. (Casanova and Struhl 1989; Sprenger et al. 1989; Stevens et al. 1990). tsl appears to be expressed by specialized follicle cells at each end of the maturing oocyte (Savant-Bhonsale and Montell 1993; Martin et al. 1994) and is found at each end of the early embryo after fertilization (Martin et al. 1994). Moreover, its restricted expression in these follicle cells appears to be critical to generate a localized terminal signal in the embryo because ectopic $t s l$ expression during oogenesis causes central portions of the early embryo to develop terminal structures (SavantBhonsale and Montell 1993; Martin et al. 1994). In 
contrast, trk activity appears to be required in the female germ line (Schüpbach and Wieschaus 1986b). As in the case of dorsoventral signal, the tor receptor appears to play a significant role both in sequestering and transducing a putative extracellular ligand that is locally generated (Sprenger and Nüsslein-Volhard 1992; Casanova and Struhl 1993), presumably as a consequence of $t s 1$ activity. Hence, trk could encode the ligand or a component that facilitates its processing or subsequent interactions with the receptor.

Here we report the cloning and sequencing of the trk gene as well as an analysis of trk transcription and the lesions associated with a series of trk mutations. We find that trk encodes a protein that is likely to be secreted and that resembles spz in two notable respects. First, it contains a domain that appears similar to a well-characterized proteolytic cleavage site in complement component 3 (Müller-Eberhad 1988). Although spz does not contain a similar site, there is compelling evidence that it is activated by proteolytic cleavage (Morisato and Anderson 1994). Second, the portion of trk carboxy-terminal to the putative cleavage site contains a similar arrangement of cysteines to that found in $\mathrm{spz}$ (Morisato and Anderson 1994). This arrangement is reminiscent of the cystine knot motif found in other families of extracellular ligands (McDonald and Hendrickson 1993). Finally, our sequence analysis of several trk mutations suggests that both the putative cleavage site as well as the conserved cysteines in the carboxy-terminal domain are essential for trk protein activity. We therefore postulate that trk encodes an extracellular ligand involved in specifying terminal body pattern and propose by analogy with spz that a cleaved form of trk constitutes the ligand for the tor receptor.

\section{Results}

\section{Cloning of the trk gene}

We have cloned the trk gene using a P-element-induced mutation $\left(t r k^{V 67-1}\right)$ provided by T. Schüpbach (Princeton University, NJ). P-element-containing phage were selected from a library made with genomic DNA from trk ${ }^{\text {V67-1 }}$ mutant embryos, and a P-element-containing phage from the trk locus was identified by cross-hybridization with cosmids from a chromosomal walk in the 31BC chromosomal interval provided by I. Whitehead and N. Clegg. Genomic DNA from this phage was then used as a hybridization probe to recover a corresponding phage from a wild-type genomic library. Southern blot analysis allowed the detection of differences between genomic DNAs derived from wild-type, $\operatorname{trk}^{V 67-1}$, and trk $k^{V 67-1}$ revertant stocks, and the region containing the $\mathrm{P}$ element was subcloned and sequenced to determine the site of insertion. Genomic DNAs from the trk region were inserted into the $\mathrm{P}\left(\mathrm{ry}^{+}\right)$transformation vector $\mathrm{C} 20$, returned to the Drosophila genome by P-element-mediated transformation, and assayed for their ability to rescue the maternal effect phenotype associated with the $t r k^{1}$ mutation. The transformation experiments showed that trk is contained within a $3-\mathrm{Kb}$ segment of genomic DNA that fully rescues the terminal patterning defects caused by loss-of-function mutations in the trk gene (Fig. 1). This rescuing genomic fragment includes sequences homologous to embryonic mRNAs derived from three transcription units, one of which we infer encodes the trk protein because it is the only unit of the three that (1) initiates within the rescuing DNA fragment (2) is entirely contained within this DNA fragment, and (3) gives rise to a transcript that is altered (shortened) by insertion of the P element associated with the $t r k^{V 67-1}$ mutation (see Fig. 1). Furthermore, we have determined the sequences of four EMS-induced point mutations in trk and each is associated with a single-amino-acid change in the putative coding sequence (see legend to Fig. 2).

Seven trk cDNAs were obtained and all are colinear with the genomic DNA, indicating that there are no introns in the trk gene. trk cDNA probes detect a transcript of $\sim 0.8 \mathrm{~kb}$ on a Northern blot (Fig. 1), similar to the size of the longest cDNAs, as well as a smaller transcript of $\sim 0.6 \mathrm{~kb}$, which appears to represent a prematurely terminated form of the $0.8-\mathrm{kb}$ transcript (Figs. 1 and 2). These transcripts are present in unfertilized eggs and early embryos but are not detected in embryos aged $>2 \mathrm{hr}$ after egg laying. In situ hybridization shows that these RNAs are present in the nurse cells, but not in the surrounding follicle cells, in agreement with the trk germ-line requirement (Schüpbach and Wieschaus 1986b); we also detect uniform expression of trk transcripts in early embryos (Fig. 1C).

\section{The predicted trk protein}

The trk cDNAs contain part or all of a single open reading frame (ORF) that could be initiated at either of two start codons at nucleotides 1998 and 2025 to generate proteins of 235 or 226 amino acids, respectively (Fig. 2); however, the sequence around the ATG at 2025 is a better match with the Drosophila consensus sequence for translational initiation (Cavener 1987). In both cases, hydropathy profiles reveal a short hydrophobic stretch at the amino terminus that obeys the rules defining a signal sequence (Fig. 2; von Hejine 1985). No other potential transmembrane domains are predicted in the ORF, suggesting that the trk protein is secreted; however, we note the presence of a short hydrophobic stretch at the carboxyl terminus that is also present in $\mathrm{spz}$ and other growth factors with the cystine knot motif. A noncanonical polyadenylation signal is present at position 2725 . In five of the seven cDNAs sequenced, a stretch of poly(A) is found 23 or 39 nucleotides downstream from this site. We note the presence of two canonical polyadenylation sites beginning at nucleotides 2549 and 2588 (dotted underline), upstream of the stop codon beginning at nucleotide 2703 . These sequences appear to function in vivo because we found single cDNAs that terminated after these sequences (one of each type out of a total of seven cDNAs sequenced) and because we observe a higher mobility band in our Northern blot analysis (Fig. 1B). These smaller transcripts could not code for the intact protein; 
A

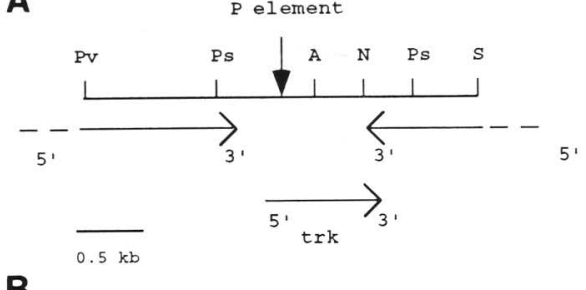

B
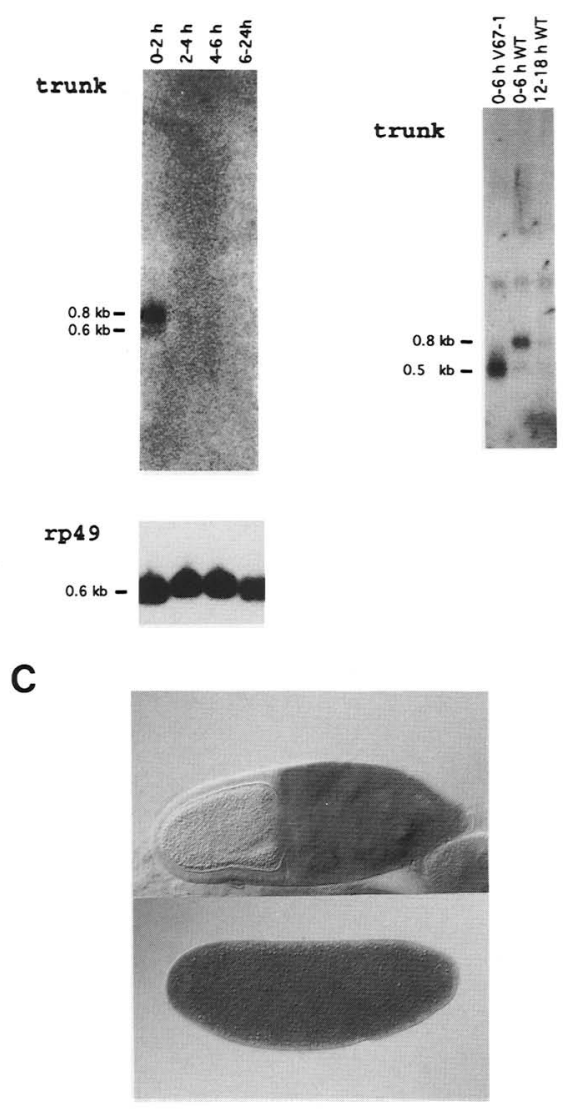

hence, we believe that they are nonfunctional. We have also found a genomic polymorphism between different strains at position 2313, where the sequence GTAGAGAAGAA is replaced by GTGGAGAA, giving rise to a predicted polypeptide with two lysines beginning at position 99 instead of the three present in the reported sequence.

Analysis of the predicted trk protein sequence reveals a stretch of 31 amino acids (amino acids 62-92) with similarity to a portion of complement component 3 (C3), which includes the site for its proteolytic cleavage to forms C3a and C3b (Müller-Eberhad 1988). For example, as shown in Figure 3, 13/31 residues are identical between this portion of trk and mouse C3 (Wetsel et al. 1984); moreover, highly conserved amino acids, which include the putative protease cleavage and binding sites (subdomains A and B), as well as the length of the intervening spacer region $(S)$ between them (Mathias et al.
Figure 1. The trk transcription unit. $(A)$ A partial restriction map of the 3004-bp PvuII-Sall fragment that rescues the trk phenotype and, hence, contains the trk gene. (A) AvaI; (N) NsiI; (Ps) $P_{s t \mathrm{I}}$ (Pv) $P_{v u I I}$ (S) Sal (see Fig. 2 for DNA sequence). Three transcription units overlap with or are contained within this region, as shown by arrows. Note that the trk transcript is the only one that initiates and is entirely contained within the rescuing DNA. The insertion site of the $P$ element associated with the $t r k^{V 67-1}$ mutation is also indicated. $(B)$ Expression of trk RNA. Northern blots of RNAs from both wild-type and $t k^{V 67-1}$ mutant embryos probed with labeled DNA derived from the Nsil-Aval genomic fragment. Note that trk transcripts are present predominantly in embryos aged $0-2 \mathrm{hr}$ following fertilization and that the size of the trk transcript is reduced in mutant embryos (the blot on the left was also probed for rp49 transcripts to confirm the integrity of each RNA sample). A smaller transcript of $\sim 0.6 \mathrm{~kb}$ is observed in wild-type embryos, which appears to be a product of premature termination (see legend to Fig. 2). (C) In situ hybridization of the nurse cell/oocyte complex (top) and early embryo (bottom) with labeled DNA complementary to the NsiI-AvaI genomic fragment. Note that trk mRNA can be detected in the nurse cells, but not the follicle cells, during oogenesis and that the transcripts appear to be uniformly distributed in early embryos.

1992), are also conserved in trk). The similarity between trk and C3 is confined to this domain; hence, trk does not appear to be a Drosophila C3 homolog. Nevertheless, the presence of this domain suggests that trk protein is proteolytically cleaved. We note that the conserved arginine immediately upstream of the putative cleavage site in trk (arrow, Fig. 3 ) is changed to a glutamine in the $t r k^{6}$ mutation. This substitution causes a complete loss of $t r k$ gene function, consistent with the possibility that cleavage is essential for trk activity.

Another feature of the trk protein is the arrangement of cysteine residues in its carboxyl terminus, which resembles that found in the carboxy-terminal portion of the spz protein (Fig. 4; Morisato and Anderson 1994). It is this portion of spz that is thought to be activated by proteolytic cleavage and to constitute the ligand for the Toll receptor (Morisato and Anderson 1994; Schneider et al. 1994). The arrangement of carboxy-terminal cysteines in trk and spz is also reminiscent of that of the cystine knot motif found in several growth factors and extracellular ligands (McDonald and Hendrickson 1993; MurrayRust et al. 1993). Other conserved features of this motif, however, are not present in either spz or trk (MurrayRust et al. 1993; N. McDonald, pers. comm.), suggesting that the arrangement of cysteines in spz and trk may define a novel structural motif.

\section{Molecular characterization of trk mutant alleles}

To gain a better understanding of the function of the trk protein we have sequenced the trk-coding region of four $t r k$ alleles that behave genetically as amorphs. In the $t r k^{3}$ mutation, the tryptophan at position 89 is changed to a stop codon and thus should result in a truncated protein. In the $\operatorname{trk}^{1}$ mutation, another tryptophan at position 211 
Figure 2. Genomic and cDNA nucleotide sequence of the trk gene and the predicted trk protein sequence. (A) Sequence of the genomic DNA comprising the trk trancription unit /nucleotide numbers refer to the sequence of the $3-\mathrm{kb}$ PvulI-Sall rescuing fragment). The nucleotide sequence from the cDNA clones is shown in upper case lettering, and the predicted amino acid sequence is shown below the nucleotide sequence beginning at nucleotide 2025. The $5^{\prime}$ ends of the isolated cDNAs were at positions 1984, 2000, 2005, 2012, 2019, 2026, and 2072. Translation could also initiate nine codons upstream at the ATG beginning at nucleotide 1998; however, the sequence around the ATG at 2025 is a better match with the Drosophila consensus sequence for translational initiation (Cavener 1987). A short hydrophobic stretch is present at the amino terminus that obeys the rules defining a signal sequence (underlined). We indicate the stretch of amino acids with similarity to the cleavage domain of complement component 3 (C3) (double underlined), which includes the putative site for its proteolytic cleavage (arrow). The cysteines present at the carboxyl terminus of the protein are also indicated. The site of the $\mathrm{P}$ insertion in $t r k^{V 67.1}$ is between nucleotides 2048 and 2049 (open arrowhead). (B) Diagram of the predicted trk protein with indication of the position of the trk mutations molecularly characterized.

is changed to a stop codon: This mutation should result in a protein that lacks the last 16 amino acids, including 3 of the cysteines of the motif present in trk and spz. Another indication of the importance of the cysteine arrangement comes from the analysis of the $t r k^{2}$ mutation,

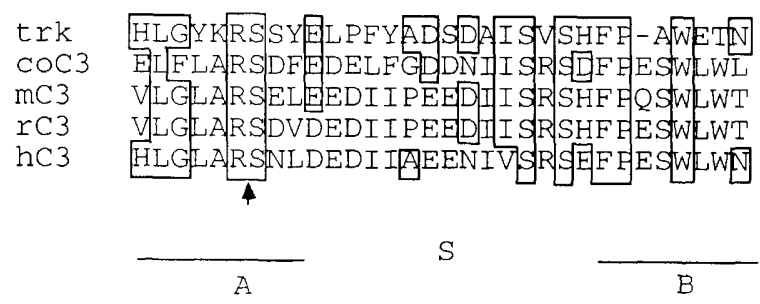

Figure 3. Protein sequence comparisons between trk and complement $\mathrm{C} 3$. Comparison of trk protein with the $\mathrm{C} 3$ cleavage site $[(\mathrm{co})$ cobra (Fritzinger et al. 1992) (m) mouse (Wetsel et al. 1984 ); (r) rat (Misumi et al. 1990); and (h) human (De Brujin et al. 1985)]. Cleavage of C3 to generate C3a and C3b (arrow) appears to depend on three distinct sub-domains designated A, B, and $\mathrm{S}$. It has been proposed that region A contains the cleavage site, region B constitutes a binding site for the protease, and region $S$ functions as a spacer, the length and acidity of which appear important for the normal cleavage event to occur (Mathias et al. 1992). All three of these subdomains appear to be conserved in the trk protein. in which the cysteine residue at position 168 is changed to a serine. Finally, in the $t r k^{6}$ mutation, the arginine at position 67 in the putative C3-like cleavage site is changed to a glutamine (trk mutants are named according to Lindsley and Zimm 1992). In summary, the molecular analysis of the trk mutant alleles supports the functional importance of the domains found in the predicted trk protein.

\section{Discussion}

\section{The role of trk in activating the receptor tor}

The terminal and ventral determinant systems in Drosophila both depend on extracellular morphogens that are locally generated in the fluid layer surrounding the embryo (Stein et al. 1991; Sprenger and Nüsslein-Volhard 1992; Casanova and Struhl 1993). In the ventral system, at least three genes (wind, pip, and ndl) function within the follicle cells that secrete the vitelline membrane surrounding the oocyte and are thought to generate products that are located ventrally in the early embryo. These products are believed to trigger a spatially localized protease cascade that cleaves $\mathrm{spz}$, thereby enabling it to bind to and activate the receptor Toll (Stein and NüssleinVolhard 1992; Morisato and Anderson 1994). Our finding that the trk gene encodes a protein that may be secreted 


\begin{tabular}{|c|c|c|c|c|}
\hline & * & * & * & $\star \star *$ \\
\hline & C WYDHFN & C KPKSFTIKVLRRKTGS & C IRINDKLILITAEKFENDYTQLWIWEEIAVNF & CC E C VMLY \\
\hline & C EGADQP & DFAANFPQSYNPI & KQHYTQQTLASIKSDGELDVVNSFKIPS & CC $K$ C ALKTG \\
\hline
\end{tabular}

Figure 4. Spatial arrangement of cysteines in the carboxy-terminal domains of trk and spz. As in the case of the cystine knot motifs in NGF, TGF- 32 , and PDGF-B, no other significant identities are apparent between the trk and $s p z$ carboxy-terminal domains and the spacing of cysteines is not strictly conserved.

and cleaved to yield a carboxy-terminal polypeptide similar to the active form of spz raises the possibility that trk and spz function in an analogous fashion. That is, trk may be secreted intact into the perivitelline fluid layer and locally activated by proteolytic cleavage to generate the ligand for the receptor tor. Because the terminal and ventral determinant systems function independently within the same extracellular fluid layer, we suppose that spz and trk would be processed by distinct biochemical pathways.

The possibility that the carboxy-terminal portion of trk functions as the tor ligand raises the question of the role of the tsl protein. tsl, like trk, is required for activity of the tor receptor; however, it is expressed in specialized follicle cells that secrete the vitelline membrane at each end of the maturing oocyte, and its protein product accumulates at the poles of the embryo, where it appears to specify terminal body pattern (Savant-Bhonsale and Montell 1993; Martin and Ollo 1994). These findings have led to the proposal that tsl might itself be the tor ligand (Martin and Ollo 1994). According to this view, the ligand-like structure of trk could reflect a signaling role upstream of the localized expression of tsl, for example, as an oocyte-to-follicle cell signal involved in specifying the differentiation of specialized border cells at each end of the oocyte. We regard this scenario as unlikely, however, because tsl expression is normal in trk mutant ovaries and the terminal phenotype caused by the absence of trk gene function cannot be rescued by heat shock-driven expression of the tsl gene (M. Furriols and J. Casanova, unpubl.). Hence, tsl appears to act upstream of trk. Instead, based on the parallels between the ventral and terminal determinant systems, and particularly on the similarities between trk and $\mathrm{spz}$, we favor the hypothesis that tsl is involved in the spatially localized processing of trk protein, a role analogous to that proposed for the follicle cell-dependent dorsoventral genes wind, pip, and ndl. Because tsl does not appear to be a protease (Savant-Bhonsale and Montell 1993; Martin et al. 1994|, we suggest that it plays some other role in restricting where or how much of the cleaved form of trk is generated or in facilitating the ability of trk to interact with tor.

\section{Materials and methods}

The trk genomic and complementary DNAs were subcloned in Bluescript and sequenced by the standard dideoxy termination method with Sequenase (U.S. Biochemical). Oligonucleotide primers corresponding to determined sequences were used in some reactions.
cDNAs from the trk region were obtained from an early embryonic cDNA library provided by R. Rivera (Karl Friedrich Bonhoeffer Institute, Göttingen, Germany). Genomic DNAs from the different mutant strains were PCR amplified and sequenced. Two independent PCR products were sequenced for each mutant strain, and the change reported in each case was the only one observed between the mutant DNA and parental wild-type DNA in which the mutation was induced. Transcripts were mapped by use of both single- and double-stranded probes derived from genomic DNA fragments for Northern blot analysis; the Northern results were also confirmed by analysis of cDNAs obtained from each of the three transcription units. Standard methods for germline transformation, Northern blot analysis, and digoxigenin whole-mount in situ hybridization were used.

\section{Acknowledgments}

We are especially grateful to Trudi Schüpbach for generously providing the $t r k^{\text {V67-1 }}$ P-element mutation and other stocks, and to Ian Whitehead and Nigel Clegg for generously providing cosmids from their genomic walk in the $3 \mathrm{lBC}$ region. We also thank Iva Greenwald and Eric Wieschaus for providing space in their laboratories for the trk genomic sequencing; Rolando Rivera for providing his early embryonic cDNA library; Nicolás Martín, Atsuko Nakanishi, and Robert Perez for their technical assistance; and Joan Collet, Iva Greenwald, Simon Greenwood, Tom Jessell, Richard Mann, Mark Peifer, and Robin Wharton for their advice and comments on the manuscript. This work was supported by the Dirección General de Investigación Cientifica y Técnica, Comissió Interdepartemental de Recerca i Innovació Tecnològica (DGICYT) and the Fundación Ramón Areces. M.F. is supported by a fellowship from the Ministerio de Educacion y Ciencia. G.S. is an Investigator of the Howard Hughes Medical Institute.

The publication costs of this article were defrayed in part by payment of page charges. This article must therefore be hereby marked "advertisement" in accordance with 18 USC section 1734 solely to indicate this fact.

\section{References}

Casanova, J. and G. Struhl. 1989. Localized surface activity of torso, a receptor tyrosine kinase, specifies terminal body pattern in Drosophila. Genes \& Dev. 3: 2025-2038.

- 1993. The torso receptor localizes as well as transduces the spatial signal specifying terminal body pattern in Drosophila. Nature 362: 152-155.

Cavener, D.R. 1987. Comparison of the consensus sequence flanking translational start sites in Drosophila and vertebrates. Nucleic Acids Res. 15: 1353-1361.

Chasan, R. and K.V. Anderson. 1993. Maternal control of dorsalventral polarity and pattern in the embryo. In The development of Drosophila melanogaster. Cold Spring Harbor Lab- 
oratory Press, Cold Spring Harbor, New York.

De Brujin, M.H.L. and G. Fey. 1985. Human complement component C3: cDNA coding sequence and derived primary structure. Proc. Natl. Acad. Sci. 82: 708-712.

Fritzinger, D.C., E.C. Petrella, M.B. Connelly, R. Bredehorst, and C.-W.Vogel. 1992. Primary structure of cobra complement component C3. J. Immunol. 149: 3554-3562.

Lindsley, D.L. and G.G. Zimm. 1992. The genome of Drosophila melanogaster. Academic Press, San Diego, CA.

Martin, J-R., A. Raibaud, and R. Ollo. 1994. Terminal pattern elements in Drosophila embryo induced by the torso-like protein. Nature 367: 741-745.

Mathias, P., C.J. Carrillo, N.E. Zepf, N.R. Cooper, and R.T. Ogata. 1992. Mutants of complement component C3 cleaved by the C4-specific Cls protease. Proc. Natl. Acad. Sci. 89: $8125-8129$.

McDonald, N.Q. and W.A. Hendrickson. 1993. A structural superfamily of growth factors containing a cystine knot motif. Cell 73: 421-424.

Misumi, Y., M. Sohda, and Y. Ikehara. 1990. Nucleotide and deduced amino acid sequence of rat complement $\mathrm{C} 3$. $\mathrm{Nu}$ cleic Acids Res. 18: 2178.

Morisato, D. and K.V. Anderson. 1994. The spätzle gene encodes a component of the extracellular signaling pathway establishing the dorso-ventral pattern of the Drosophila embryo. Cell 76: 677-688.

Müller-Eberhad, H.J. 1988. Molecular organization and function of the complement system. Annu. Rev. Biochem. 57: 321347.

Murray-Rust, J., N.Q. McDonald, T.L. Blundell, M. Hosang, C. Oefner, F. Winkler, and R.A. Bradshaw. 1993. Topological similarities in TGF- $\beta 2$, PDGF-BB, and NGF define a superfamily of polypeptide growth factors. Curr. Biol. Struct. 1: 153-159.

Nüsslein-Volhard, C., H.G. Fronhöfer, and R. Lehmann. 1987. Determination of anteroposterior polarity in Drosophila. Science 238: 1675-1681.

O'Hare, K. and G.M. Rubin. 1983. Structures of P transposable elements and their sites of insertion and excision in the Drosophila melanogaster genome. Cell 34: 25-35.

Savant-Bhonsale, S. and D.J. Montell. 1993. torso-like encodes the localized determinant of Drosophila terminal pattern formation. Genes \& Dev. 7: 2548-2555.

Schneider, D.S., Y. Jin, D. Morisato, and K. Anderson. 1994. A processed form of spätzle protein defines dorso-ventral polarity in the Drosophila embryo. Development 120: 12431250.

Schüpbach, T. and E. Wieschaus. 1986. Germ-line autonomy of maternal-effect mutations altering the embryonic body pattern of Drosophila. Dev. Biol. 113: 443-338.

Sprenger, F. and C. Nüsslein-Volhard. 1992. Torso receptor activity is regulated by a diffusible ligand produced at the extracellular terminal regions of the Drosophila egg. Cell 71: 987-1001.

Sprenger, F., L.M. Stevens, and C. Nüsslein-Volhard. 1989. The Drosophila gene torso encodes a putative receptor tyrosine kinase. Nature 338: 478-483.

Stein, D. and C. Nüsslein-Volhard. 1992. Multiple extracellular activities in Drosophila egg perivitelline fluid are required for establishment of embryonic dorsal-ventral polarity. Cell 68: $429-440$.

Stein, D., S. Roth, E. Vogelsang, and C. Nüsslein-Volhard. 1991. The polarity of the dorsoventral axis in the Drosophila embryo is defined by an extracellular ligand. Cell 65: 725-735.

Stevens, L.M., H.G. Fronhöfer, M. Klinger, and C. NüssleinVolhard. 1990. Localized requirement for torso-like expres- sion in follicle cells for development of the terminal anlagen of the Drosophila embryo. Nature 346: 660-663.

St. Johnston, D. and C. Nüsslein-Volhard. 1992. The origin of pattern and polarity in the Drosophila embryo. Cell 68: 201219

von Hejine, G. 1985. A new method for predicting signal sequence cleavage sites. J. Mol. Biol. 184: 99-105.

Wetsel, R.A., A. Lundwall, F. Davidson, T. Gibson, B.F. Tack, and G.H. Fey. 1984. Structure of murine complement component C3. J. Biol. Chem. 259: 13857-13862. 


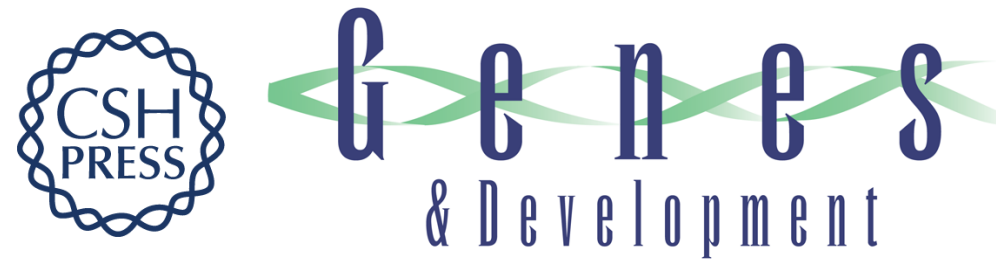

\section{Similarities between trunk and spätzle, putative extracellular ligands specifying body pattern in Drosophila.}

J Casanova, M Furriols, C A McCormick, et al.

Genes Dev. 1995, 9:

Access the most recent version at doi:10.1101/gad.9.20.2539

References This article cites 25 articles, 8 of which can be accessed free at:

http://genesdev.cshlp.org/content/9/20/2539.full.html\#ref-list-1

License

Email Alerting

Service

Receive free email alerts when new articles cite this article - sign up in the box at the top right corner of the article or click here.

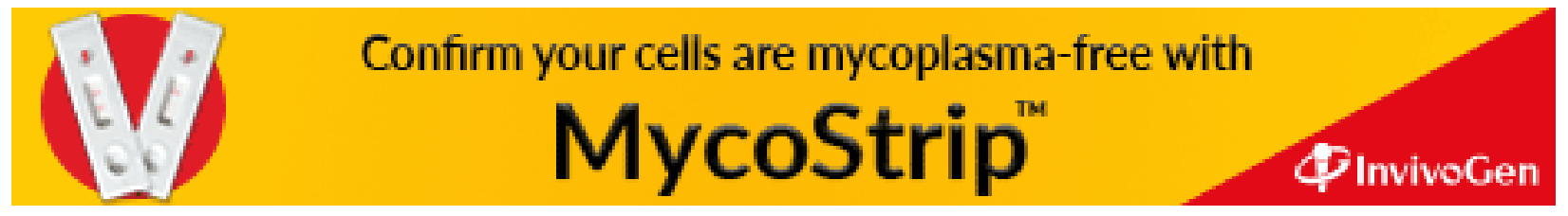

